\title{
Single-insertion technique for anesthetizing the inferior alveolar nerve, lingual nerve, and long buccal nerve for extraction of mandibular first and second molars: a prospective study
}

\author{
Benny Joseph ${ }^{1}$, Nithin Kumar ${ }^{2}$, Suresh Vyloppilli ${ }^{3}$, Shermil Sayd ${ }^{4}$, KP Manojkumar', Depesh Vijaykumar ${ }^{1}$ \\ ${ }^{I}$ Department of Oral and Maxillofacial Surgery, Kunhitharuvai Memorial Charitable Trust (KMCT) Dental College, Calicut, India, \\ ${ }^{2}$ Department of Oral Surgery, Dental Faculty, Tishk International University, Erbil, Iraq, \\ ${ }^{3}$ Department of Oral and Maxillofacial Surgery, Malankara Orthodox Syrian Church Hospital and Medical College, Ernakulum, \\ ${ }^{4}$ Department of Oral and Maxillofacial Surgery, Kannur Dental College, Kannur, India
}

\begin{abstract}
J Korean Assoc Oral Maxillofac Surg 2020;46:403-408)
Objectives: Appropriate and accurate local anesthetic (LA) techniques are indispensable in the field of oral and maxillofacial surgery to obtain a satisfactory outcome for both the operating surgeon and the patient. When used alone, the inferior alveolar nerve block (IANB) technique requires supplemental injections like long buccal nerve block for extraction of mandibular molars leading to multiple traumatic experiences for the patient. The aim of this study was to anesthetize the inferior alveolar, lingual, and long buccal nerves with single-needle penetration requiring a minimal skillset such as administering a conventional IANB through introduction of the Benny Joseph technique for extraction of mandibular molars.

Materials and Methods: This was a prospective study conducted in the Department of Oral and Maxillofacial Surgery, Kunhitharuvai Memorial Charitable Trust (KMCT) Dental College, Calicut, India. The duration of the study was 6 months, from June to November 2017, with a maximum sample size of 616 cases. The LA solution was $2 \%$ lignocaine with 1:100,000 adrenaline. The patients were selected from a population in the range of 20 to 40 years of age who reported to the outpatient department for routine dental extraction of normally positioned mandibular right or left first or second molars.

Results: Of the 616 patients, 42 patients (6.8\%) required re-anesthetization, a success rate of $93.2 \%$. There were no complications such as hematoma formation, trismus, positive aspiration, and nerve injuries. None of the cases required re-anesthetization in the perioperative period.

Conclusion: The Benny Joseph technique can be employed and is effective compared with conventional IANB techniques by reducing trauma to the patient and also requires less technique sensitivity.
\end{abstract}

Key words: Benny Joseph technique, Lingual nerve block, Inferior alveolar nerve block, Long buccal nerve block

[paper submitted 2019. 10. 6 / revised 2019. 12. 13 / accepted 2019. 12. 17]

\section{Introduction}

Appropriate and accurate local anesthetic (LA) techniques are indispensable in oral and maxillofacial surgery to obtain a satisfactory outcome for both the operating surgeon and the patient. For these purposes, various surgical techniques have

\author{
Shermil Sayd \\ Department of Oral and Maxillofacial Surgery, Kannur Dental College, \\ Anjarakandy, Kannur 670612, India \\ TEL: +91-484-2760251 FAX: +91-484-2760409 \\ E-mail:shermil12@gmail.com \\ ORCID: https://orcid.org/0000-0002-1765-8955
}

(a) This is an open-access article distributed under the terms of the Creative Commons Attribution Non-Commercial License (http://creativecommons.org/ licenses/by-nc/4.0/), which permits unrestricted non-commercial use, distribution, and reproduction in any medium, provided the original work is properly cited. Copyright (C) 2020 The Korean Association of Oral and Maxillofacial Surgeons. All rights reserved. been utilized for the maxilla and mandible. To obtain anesthesia in the mandible, various techniques like the inferior alveolar nerve block (IANB), Spix, Vazirani-Akinosi, and Gow-Gates techniques are available ${ }^{1}$. The Spix IANB is the most commonly used technique, but there have been reports of its failure to achieve adequate anesthesia ${ }^{2,3}$. When used alone, the IANB technique requires supplemental injections like long buccal nerve block for extraction of mandibular molars, leading to multiple traumatic experiences for the patient. Conventional mandibular nerve block techniques like Vazirani-Akinosi and Gow-Gates require a larger volume of LA solution and a well-experienced surgeon. The technical acuity required and the lack of bony stops for these techniques discourage their use by normal dental practitioners even though they are single-penetration techniques ${ }^{4,5}$. 
Various techniques are currently employed for mandibular tooth extraction or procedures, and all have their own advantages such as increased spread of anesthesia and increased patient comfort and disadvantages such as requiring increased skills, technical sensitivity, number of failures, and multiple penetrations. Therefore, the aim of this study was to anesthetize the inferior alveolar nerve along with the lingual and long buccal nerves with a single needle penetration requiring a minimal skillset such as administering a conventional IANB (Spix technique, Fischer 1-2-3 technique, etc.), aiding in reduction of the number of penetrations to the patient and being comparatively less technique sensitive. A new technique called the Benny Joseph single insertion IANB technique will be introduced in this study.

\section{Materials and Methods}

This was a prospective study conducted in the Department of Oral and Maxillofacial Surgery, Kunhitharuvai Memorial Charitable Trust (KMCT) Dental College, Calicut, India. Formulation of the outline of the study was based on STROBE (Strengthening the Reporting of Observational Studies in Epidemiology) guidelines and Institutional Ethics Committee/Institutional Review Board of KMCT Dental College approval (IEC/IRB No. KMCTDC/IEC/2017/05). The patients were selected from a population between 20-40 years of age who reported to the outpatient department for routine

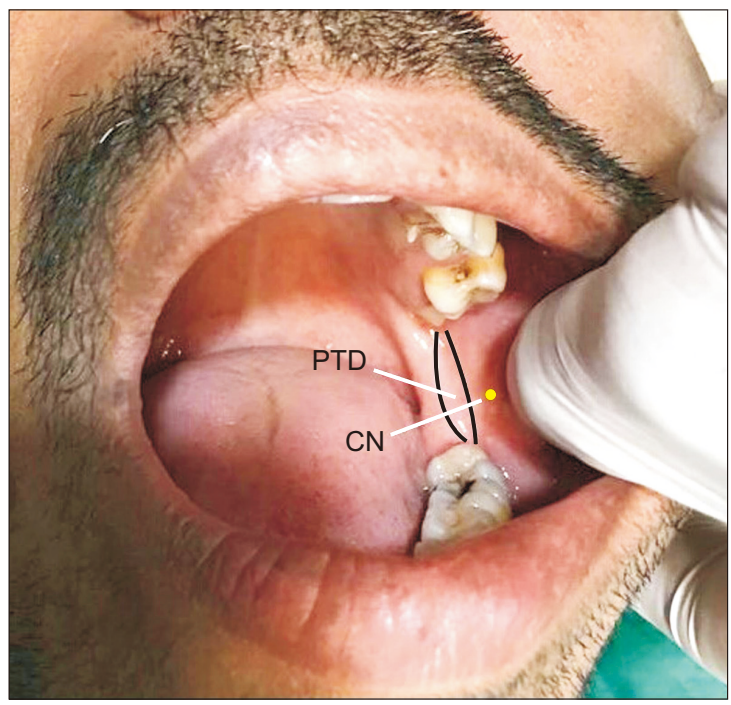

Fig. 1. Identification of the landmarks and points of needle insertion. (PTD: pterygotemporal depression, $\mathrm{CN}$ : coronoid notch)

Benny Joseph et al: Single-insertion technique for anesthetizing the inferior alveolar nerve, lingual nerve, and long buccal nerve for extraction of mandibular first and second molars: a prospective study. J Korean Assoc Oral Maxillofac Surg 2020 dental extraction of normally positioned mandibular right or left first or second molars. The procedure and complications were discussed with the patient, and informed consent was obtained. Patients who reported no systemic disease and had no historical incidence of allergy to the LA solution were included in the study. Patients with grade II or grade III mobility or with chronic generalized periodontitis were excluded. A single operator performed all the LA administration after test dosing and following aseptic procedures with the help of a $2.5 \mathrm{~mL}$ syringe with a 24-gauge needle $25 \mathrm{~mm}$ in length. The duration of the study was 6 months, from June to November 2017 . The LA solution used was $2 \%$ lignocaine with 1:100,000 adrenaline.

Technique:

(1) The patient was positioned in a semi-supine position so that the mandibular occlusal plane was parallel to the floor during opening of the oral cavity.

(2) The operator's thumb was placed over the maximum concavity of the anterior border of the ramus of the mandible, the coronoid notch.(Fig. 1) Following this, the pterygomandibular raphe was identified extending from the pterygoid hamulus superiorly to the retromolar area inferiorly.

(3) The site of insertion of the needle was $6-8 \mathrm{~mm}$ above the occlusal plane and 4-6 mm anterior to the deepest point of the pterygotemporal depression (PTD).(Fig. 2)

(4) The technique commenced with the syringe barrel on the ipsilateral side (Fig. 3) to the point of insertion.

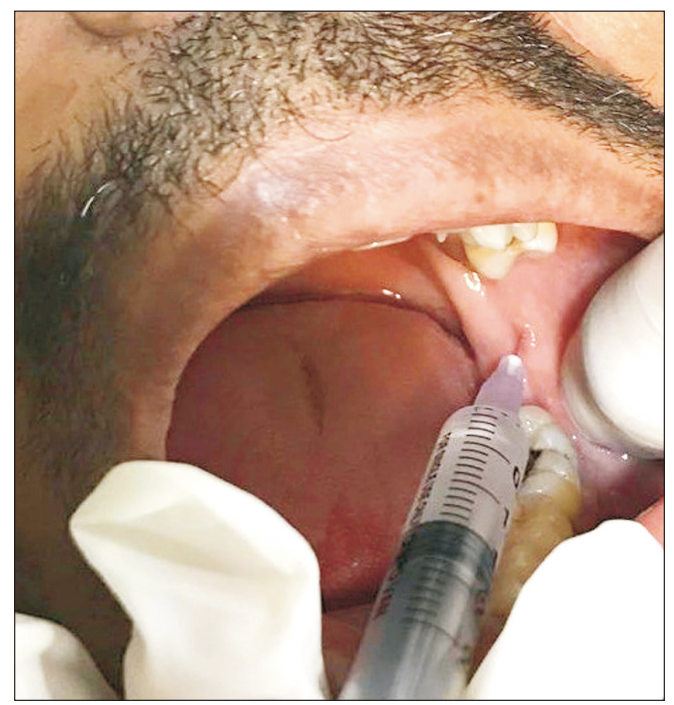

Fig. 2. Needle insertion at the deepest point of the pterygotemporal depression.

Benny Joseph et al: Single-insertion technique for anesthetizing the inferior alveolar nerve, lingual nerve, and long buccal nerve for extraction of mandibular first and second molars: a prospective study. J Korean Assoc Oral Maxillofac Surg 2020 
(5) After initial penetration, the needle was advanced posteriorly over the medial surface of the ramus of the mandible, circumventing the dyke created by the internal oblique ridge. Next, the syringe barrel was repositioned to the midline (between the central incisors) and advanced posteriorly until the entire length of the needle was inside the tissue. It was imperative during this entire procedure to ascertain that the needle was close to the medial surface of the ramus (Change in direction of the needle was performed only when it was halfway inserted and crossed the dyke created by the internal oblique ridge, after which the needle was inserted to full length, reducing the risk of needle breakage.).

(6) The depth of penetration was limited to $25 \mathrm{~mm}$ based on evidence provided by Malamed ${ }^{5}$ on the mandibular foramen limit to a distance between 20-25 $\mathrm{mm}$ from the anterior border of the ramus. This also ensured that, when the needle was completely inserted, it would be approximately superior to the inferior alveolar nerve (IAN) entry into the mandibular foramen, where $1.5 \mathrm{~mL}$ of LA was deposited to anesthetize the inferior alveolar nerve.

(7) Considering the probability of anatomical variation, it is recommended that LA solution be deposited using a needle of either $21 \mathrm{~mm}$ or $24 \mathrm{~mm}$ in length to reduce failure and to ensure that the solution is deposited as close to the IAN as possible.

(8) After successful deposition of the solution, the syringe was withdrawn 10-15 $\mathrm{mm}$ and moved to the ipsilateral side

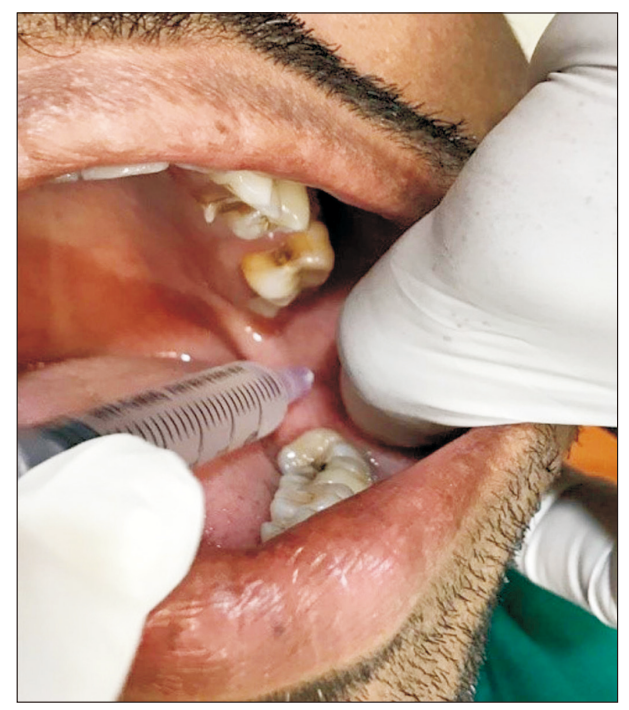

Fig. 3. Retraction of buccal soft tissues and ipsilateral placement of the needle during the initial steps of injection.

Benny Joseph et al: Single-insertion technique for anesthetizing the inferior alveolar nerve, lingual nerve, and long buccal nerve for extraction of mandibular first and second molars: a prospective study. J Korean Assoc Oral Maxillofac Surg 2020 for deposition of $0.5 \mathrm{~mL}$ of LA to anesthetize the lingual nerve.

(9) This was followed by removal of the thumb from the coronoid notch for use in lateral retraction of the buccal mucosa.

(10) Once retraction was complete, the syringe barrel was moved to the contralateral (to the first molar) side with simultaneous withdrawal to a distance of 5-6 mm or until it crossed the internal oblique ridge prominence, allowing the needle tip to rest on the medial surface of the ramus of the mandible anterior to the internal oblique ridge. Once in position, $0.5 \mathrm{~mL}$ of LA solution was deposited to anesthetize the long buccal nerve.(Fig. 4)

Effectiveness of the aforementioned technique was assessed both subjectively and objectively. The following methods were utilized for assessment of anesthesia.

1) Objective assessment:

- A sharp dental explorer was applied to the gingival tissues in front of the lower premolars on the side of the extraction to assess IAN anesthesia.

- The half of the tongue on the side of extraction was tested with a probe to assess lingual nerve anesthesia.

- A sharp dental explorer was applied to the gingival tissues adjacent to the molar to be extracted to assess long buccal nerve anesthesia.

- Use of an electric pulp tester to determine absence of response to the maximal output of the tooth to be extracted.

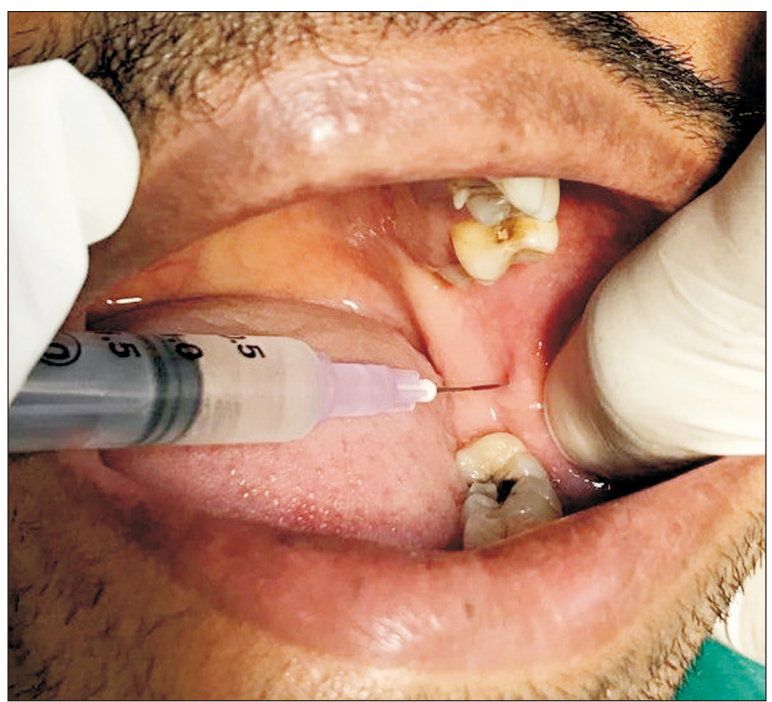

Fig. 4. Contralateral placement of the syringe for administration of inferior alveolar nerve block after crossing the internal oblique ridge.

Benny Joseph et al: Single-insertion technique for anesthetizing the inferior alveolar nerve, lingual nerve, and long buccal nerve for extraction of mandibular first and second molars: a prospective study. J Korean Assoc Oral Maxillofac Surg 2020 
2) Subjective assessment by questioning:

- Does your lip on the surgical side feel numb compared to the non-surgical side?

- Does the front side of your tongue on the surgical side feel numb compared to the non-surgical side?

The patient's response to every test was recorded using a chart in commercially available software. Negative responses implied that the corresponding nerve was anesthetized. Probe testing commenced 3 minutes after injection and repeated every two minutes after the first test for a total of 4 tests. Failure to elicit a negative response was considered a failure of this technique. According to the literature, the above-mentioned tests are the most common practical clinical tests to ensure objective anesthesia before exodontia ${ }^{1,5}$.

\section{Results}

A total of 616 patients was willing to take part in the study and provided informed consent. Totals of 270 male patients and 346 female patients comprised the study group, and the mean age was $29.9 \pm 5.9$ years. Since our institution caters to people with lower socioeconomic status, the most common reason for tooth removal was caries $(48.9 \%)$, followed by fractured restoration for which the patient refused to undergo root canal therapy (15.4\%). The remainder of the etiologies and their percentage constitution were 1) root canal treatment failure $(10.7 \%), 2)$ fractured crown $(8.1 \%), 3)$ extraction of molars following referral from the Department of Orthodontics who were otherwise asymptomatic and were not willing to under routine extraction $(4.1 \%), 4)$ trauma $(5.2 \%)$, and 5 ) periodontitis (7.6\%). From the sample size of 616 patients, 42 patients $(6.8 \%)$ required re-anesthetization, a success rate of $93.2 \%$. There was a $0 \%$ incidence of complications such as hematoma formation, trismus, positive aspiration, and nerve injuries. None of the cases required re-anesthesia during the perioperative period.

\section{Discussion}

In history, the first recorded case of neuro-regional anesthesia was achieved by William S. Halsted and Richard J. Hall in $1884^{6}$, through administration of a solution of cocaine in the vicinity of the mandibular foramen. Since then, a plethora of advancements has been used for effective anesthetization of the IAN and associated nerves for extraction of mandibular posterior teeth.

The Spix technique is the first choice for anesthetization of the IAN if any invasive procedure is indicated in mandibular posterior teeth ${ }^{7}$. This technique utilizes the mandibular lingula by reversibly blocking IAN conduction before it enters the mandibular foramen in the pterygomandibular space ${ }^{8,9}$, with success rates varying from $71 \%-87 \%{ }^{10}$. This technique necessitates separate administration for anesthetization of the long buccal nerve. In addition, there is a plethora of other techniques claiming to be more effective with decreased incidence of intravascular injection and damage to the IAN ${ }^{11}$.

The Gow-Gates and Vazirani-Akinosi techniques also are single-injection techniques for anesthesia in the posterior mandibular region. Various studies have shown a high incidence of failure to achieve anesthesia with the Gow-Gates technique, especially with an inexperienced $\operatorname{surgeon}^{3,12,13}$. Another recognized disadvantage of the Gow-Gates technique is the slower onset of anesthesia. According to Agren and Danielsson ${ }^{14}$, the onset of action can range from 10 to 30 minutes and rarely persists to 45 minutes. In addition, the recommended amount of LA required to produce desirable results for the Gow-Gates technique is $3 \mathrm{~mL}^{15}$. The VaziraniAkinosi technique is employed primarily when the patient suffers from trismus and is technique-sensitive because of the absence of bony landmarks for injection guidance, exponentially increasing the chances for injury to the pterygoid plexus $^{3}$. According to Malamed ${ }^{5}$, closed mouth nerve block techniques have greater failure rates than conventional IANB. Despite the advantages of these techniques ${ }^{6}$, most dental professionals do not prefer either of the above-mentioned techniques because of the increased skill set required.

The Fischer 1-2-3 technique relies on identification of anatomical landmarks for administration. Failure to identify these will lead to failure of anesthesia. In addition, penetration and deposition of LA solution depend on length of needle penetration, which is arbitrary as there are no markings on needles. This can cause difficulty for novice surgeons. Overpenetration and deposition will lead to unwanted effects such as facial palsy ${ }^{16}$.

When discussing our technique, the Benny Joseph technique described by Thangavelu et al. ${ }^{16}$ in 2012, the needle is inserted 6 to $8 \mathrm{~mm}$ above the mandibular occlusal plane and 4 to $6 \mathrm{~mm}$ anterior to the PTD, with simultaneous ipsilateral placement of the syringe barrel. With our approach, we were able to avoid multiple bony contacts during administration of LA solution, which decreased trauma to and increased comfort of the patient. In contrast to the methods described by Malamed ${ }^{5}$, the Benny Joseph technique is non-specific and does not depend upon vertical or horizontal lines, allow- 
ing the operator a considerable margin of error and increased chance of success ${ }^{17}$.

Most of the techniques depend upon identification of soft tissue landmarks for anesthetic administration. However, our technique, the Benny Joseph technique, depends on identification of the bony landmark of the internal oblique ridge. This increases the percentage of successful administrations and is easier for novices.

Unlike other techniques, the Benny Joseph technique is aided by early identification of the internal oblique ridge during the first few millimeters of needle insertion. This provides the surgeon easy identification of the landmarks and simplifies further advancements of the needle, reducing the chances of failure of anesthesia. Although not related to this study, other surgeons in the Department of Oral and Maxillofacial Surgery have started using this technique in their day-to-day surgical practice and have noted reduced percentage of failure.

In this study, we compared the effectiveness of the technique in an objective assessment; no consideration was given to the subjective aspect. This constitutes a drawback of this study. To establish a good doctor-patient relationship, it is imperative that the operator employ a less traumatic and less painful anesthetic technique. This study did not demonstrate increased patient comfort with the technique. We assume that this it is more comfortable based on postsurgical comments from patients with previous experience of mandibular extraction. Additional studies must be conducted to assess the subjective outcomes of this technique.

\section{Conclusion}

The Benny Joseph technique can be employed and is effective compared with conventional IANB techniques by reducing trauma to the patient and requiring less technique precision because of the landmarks employed. Additional studies are necessary for subjective assessment of this technique to obtain data regarding patient compliance and pain during the procedure.

\section{ORCID}

Benny Joseph, https://orcid.org/0000-0002-5659-3218

Nithin Kumar, https://orcid.org/0000-0001-6137-2391

Suresh Vyloppilli, https://orcid.org/0000-0002-9423-3774

Shermil Sayd, https://orcid.org/0000-0002-1765-8955

KP Manojkumar, https://orcid.org/0000-0001-8865-3812
Depesh Vijaykumar, https://orcid.org/0000-0002-3886-8994

\section{Authors' Contributions}

B.J. invented, performed and taught the technique along with overall review of the entire study. N.K., S.V., and S.S. were involved in further implementation of the technique on a research level including study design ethics committee approval, patient consent, data collection, recording and creation of the manuscript. K.P.M. was involved with the overall conduction of the study and D.V. associated with the patient education, motivation, informed consent, data entry and also with manuscript preparation and evaluation.

\section{Ethics Approval and Consent to Participate}

The study was approved by the Institutional Ethics Committee/Institutional Review Board of KMCT Dental College approval (IEC/IRB No. KMCTDC/IEC/2017/05), and informed consent was obtained.

\section{Conflict of Interest}

No potential conflict of interest relevant to this article was reported.

\section{References}

1. Kohler BR, Castellón L, Laissle G. Gow-Gates technique: a pilot study for extraction procedures with clinical evaluation and review. Anesth Prog 2008;55:2-8. https://doi.org/10.2344/00033006(2008)55[2:GTAPSF]2.0.CO;2

2. Madan GA, Madan SG, Madan AD. Failure of inferior alveolar nerve block: exploring the alternatives. J Am Dent Assoc 2002;133:843-6. https://doi.org/10.14219/jada.archive.2002.0298

3. Dover WR. The mandibular block injection--why it sometimes fails. Oral Health 1971;61:12-4.

4. Young ER, D'Aguiam G. Successful mandibular anesthesia following numerous unsuccessful attempts: a case report. J Can Dent Assoc 1993;59:845, 848-50.

5. Malamed SF. Handbook of local anesthesia. 6th ed. St. Louis: Elsevier; 2013.

6. Johnson TM, Badovinac R, Shaefer J. Teaching alternatives to the standard inferior alveolar nerve block in dental education: outcomes in clinical practice. J Dent Educ 2007;71:1145-52.

7. Suazo Galdames IC, Cantín López MG, Zavando Matamala DA. Inferior alveolar nerve block anesthesia via the retromolar triangle, an alternative for patients with blood dyscrasias. Med Oral Patol Oral Cir Bucal 2008;13:E43-7.

8. Pipa-Vallejo A, García-Pola-Vallejo MJ. Local anesthetics in dentistry. Med Oral Patol Oral Cir Bucal 2004;9:440-3; 438-40.

9. Boronat López A, Peñarrocha Diago M. Failure of locoregional anesthesia in dental practice. Review of the literature. Med Oral Patol Oral Cir Bucal 2006;11:E510-3.

10. Kaufman E, Weinstein P, Milgrom P. Difficulties in achieving 
local anesthesia. J Am Dent Assoc 1984;108:205-8. https://doi. org/10.14219/jada.archive. 1984.0470

11. Khalil H. A basic review on the inferior alveolar nerve block techniques. Anesth Essays Res 2014;8:3-8. https://doi. org/10.4103/0259-1162.128891

12. Levy TP. An assessment of the Gow-Gates mandibular block for third molar surgery. J Am Dent Assoc 1981;103:37-41. https://doi. org/10.14219/jada.archive. 1981.0467

13. Malamed SF. The Gow-Gates mandibular block. Evaluation after 4,275 cases. Oral Surg Oral Med Oral Pathol 1981;51:463-7. https://doi.org/10.1016/0030-4220(81)90001-3

14. Agren E, Danielsson K. Conduction block analgesia in the mandible. A comparative investigation of the techniques of Fischer and Gow-Gates. Swed Dent J 1981;5:81-9.

15. Kafalias MC, Gow-Gates GA, Saliba GJ. The Gow-Gates technique for mandibular block anesthesia. A discussion and a mathematical analysis. Anesth Prog 1987;34:142-9.

16. Thangavelu K, Kannan R, Kumar NS. Inferior alveolar nerve block: alternative technique. Anesth Essays Res 2012;6:53-7. https://doi.org/10.4103/0259-1162.103375

17. Quinn JH. Inferior alveolar nerve block using the internal oblique ridge. J Am Dent Assoc 1998;129:1147-8. https://doi.org/10.14219/ jada.archive. 1998.0392

How to cite this article: Joseph B, Kumar N, Vyloppilli S, Sayd S, Manojkumar KP, Vijaykumar D. Single-insertion technique for anesthetizing the inferior alveolar nerve, lingual nerve, and long buccal nerve for extraction of mandibular first and second molars: a prospective study. J Korean Assoc Oral Maxillofac Surg 2020;46:403-408. https://doi.org/10.5125/jkaoms.2020.46.6.403 